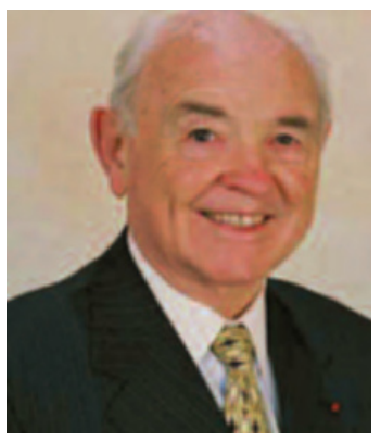

Yues Cotrel, MD

\section{A SPECIAL RELATIONSHIP WITH SCOLIOSIS}

My first encounter with scoliosis was in Berck, in 1948. I was doing at Institut Calot what I thought would be a three-week replacement, which turned out to be a nearly thirty year-commitment! At first, I learnt how to impose on patients the techniques which had not been changed since Abbott's visit in 1910; I tried to improve them. With P. Stagnara in Lyon or P. Queneau in Paris, we often discussed our ideas and techniques. When J. Cauchoix performed the first arthrodesis in 1953, the patient would have to lie in a cast for about 10 to 12 months, until a solid bone fusion would be achieved!

In 1958, a major event changed many things: I was granted the opportunity to spend 6 months visiting the major scoliosis centers in the USA, studying their techniques. Renowned specialists such as Cobb, Risser, Ponseti, Moe, and Blount shared - but also enabled me to discuss - their methods, which would vary from a center to another. From this unique experience new techniques were developed, such as the EDF plaster cast, the pre-operative traction, or even the "Device for Transverse Traction" (D.T.T.).

In 1975, I was forced to leave the growing activity of my department for health reasons. R. Seringe and later D. Chopin skilfully replaced me whilst I headed to Brittany for a dreaded early retirement. Instead of resting, I spent hours working out the implantable instrumentation, which would have been necessary to obtain a three-dimensional correction of the spine and prevent the patient from the long-duration postoperative immobilization in a plaster corset. After 3 years of research, Sofamor technicians produced the new implantable instrumentation made of rods, hooks, screws and crosspieces. This new instrumentation was implanted for the first time in my presence, by J. Dubousset, on Jan. 21st, 1983, in Paris, at Saint Vincent de Paul Hospital. It was named C.D. A bit later, M. Guillaumat implanted the first C.D. on an adult patient, at Saint Joseph Hospital. In 1985, I participated to the first implantation of the CD pedicle screw with R. Roy-Camille, assisted by C. Mazel, at Pitié Salpétrière Hospital. As at today's date, over a million patients throughout the world were operated on with the CD instrumentation or its by-products. Thanks to everyone's involvement and through entities such as the GICD, the C.D. and its by-products became widely used throughout the world under various names for many different indications of spinal surgery.

In 1999, I decided to continue this special relationship with scoliosis through the creation of a research Foundation, at the Institut de France (and a subsidiary in Memphis). The first research theme of the Fondation Yves Cotrel pour la Recherche en pathologie rachidienne is the etiology of Idiopathic Scoliosis, aiming to answer "old" questions: Why? How?

The Foundation wants to mobilize "beyond any boundaries" the most experienced teams in the disciplines most likely to be concerned, toward one goal: search and find the elements enabling the identification of "idiopathic scoliosis", predict their evolution, simplify the treatments and above all prevent their apparition. At the present time, over 80 researchers based in America, Asia and Europe are supported by the Foundation. The principal investigators regularly meet in Paris, at the Institut de France to exchange views and practices, discuss and work together on this common mission. 